\title{
HUELLAS CERVANTINAS EN EL CICLO FARSESCO DE FEDERICO GARCÍA LORCA ${ }^{1}$
}

\author{
Marta Cobo \\ Universitat de Barcelona
}

\begin{abstract}
RESUMEN: A lo largo de toda su vida Federico García Lorca declaró en varias ocasiones la deuda para con el teatro del Siglo de Oro, y concretamente, los entremeses de Miguel de Cervantes. Los entremeses se convierten, en manos del dramaturgo granadino, en la raíz a partir de la cual poder dar forma al entramado bajo el que se tejen las piezas del ciclo farsesco. Los entremeses cervantinos aparecen así como fuente de personajes, temas y tonos humanos con los que el poeta escribe tres farsas en las que consigue retomar temas tradicionales para construir un espacio mítico, universal y atemporal que se convierte en espejo del mundo que ahoga a aquellos individuos que viven fuera del margen establecido por la sociedad.
\end{abstract}

PALABRAS CLAVE: Entremés, Cervantes, Lorca, farsas, libertad, tradición.

\section{THE PRESENCE OF CERVANTES'S TRACES IN THE FARCICAL CYCLE OF FEDERICO GARCÍA LORCA}

\begin{abstract}
Along his life, Federico García Lorca declared several times his debt with the Golden Age Theatre, especially with the entremeses or short plays of Miguel de Cervantes. The entremeses become, in the hands of the playwright from Granada, the root of which shape can be given to the framework in which farcical cycle is spun. The Cervantes's entremeses appeared as a source of characters, subject matters and human tones with which the poet writes three farces in which aims to reintroduce traditional subject matters to build up a mythical, universal and timeless space that becomes the world's mirror which stifles those individuals who stay out of what was established by society.
\end{abstract}

KEYWORDS: Entremés, Cervantes, Lorca, farce, freedom, tradition.

1. Este trabajo se inscribe dentro del Grupo de Investigación Consolidado 2014 SGR 941, "Aula Música Poética”, financiado por la Generalitat de Catalunya, del cual formo parte como investigadora en formación. 
En 1933, Federico García Lorca, afirmaba cómo los entremeses cervantinos se habían convertido en "farsa y norma que llega a ser como el tuétano del verdadero teatro, gráfico de hueso donde la máscara día y noche llora y sonríe desde la aorta griega donde nació la escena" (García Lorca 1997: 224). El género breve por excelencia de todo el teatro áureo se convertía para el dramaturgo granadino en un regreso a las formas primitivas y ancestrales que le permitía, a través de la comedia, ahondar en las miserias del alma humana. Es por todo ello que la intención de este trabajo es observar el hilo con el que se unen tradición y modernidad bajo las tres piezas que conforman el retablo en que se convierte el ciclo farsesco. Un retablo que el poeta escribirá, retocará y pulirá durante toda su vida, y en el que toma como punto de partida la influencia del género del entremés, escogiendo como referencias principales, por un lado, al creador y maestro del escritor manchego, Lope de Rueda, y por otro, al hito cumbre del género: Miguel de Cervantes, intentando con ello trazar ese fino hilo que une a maestros y discípulos en las distintas formas que ha ido tomando el teatro breve, concretamente el entremés y la farsa, a lo largo de la historia del teatro; una querencia y un "recuerdo no se limita, ni mucho menos, a la reiteración mecánica de situaciones tipificadas" (Canavaggio 1983: 142); sino a la aprehensión de todo un mundo.

Pese a la evolución que sufre el género entre los primeros pasos de Lope de Rueda $^{2}$ y la mayoría de edad que alcanza con Miguel de Cervantes gracias a la publicación de sus ocho entremeses en 1615, hay dos características que vertebran y definen, a lo largo de sus distintas transformaciones, estas piezas breves tan prolijas en el Siglo de Oro: por un lado, la brevedad, pues debe ser una pieza corta para que así sea posible ser insertada entre los actos de la comedia; y por otro lado, debe traslucir comicidad, es decir, debe despertar la risa y el divertimento entre el auditorio. Comicidad y brevedad, necesarias e imprescindibles en una pieza teatral, que a la vez hunde sus raíces en la fiesta pagana del Carnaval, ya que en ella se produce "el desfogue exaltado de los instintos, la glorificación del comer y beber [...], la jocosa licencia que se regodea con los engaños conyugales, con el escarnio del prójimo, y la befa tanto más reída cuanto más pesada" (Asensio 1971: 20). Tres

2. [...] género literario segregado por otro género literario, destinado a un público de ciudad y urbanizado [...], lleva sin embargo al plano dramático rastros y reliquias de una comunidad más ligada a la naturaleza, las estaciones y el calendario. En su repertorio recoge unos tipos y un espíritu cómico enraizados en la celebración cristiana del Corpus y la pagana del Carnaval (Asensio 1971: 19-20). 
elementos que hicieron que el entremés se convirtiera en el molde perfecto para jugar con la transgresión de lo establecido y en el contrapunto excelente a la comedia nueva de Lope de Vega; el entremés se convierte así no solo en una espacio con el que poner en jaque toda una serie de valores sociales, sino también en una forma de crítica contra el modelo teatral establecido por la comedia áurea:

\footnotetext{
El tono crítico contra el mundo del teatro se refleja en unas obras en que se aprecia también una reacción contra tópicos conflictivos de un mundo cerrado, que se eleva como muy distinto a otro distante al tiempo en que el arte dramático cervantino había triunfado (Huerta Calvo 2008: 153).
}

Pequeñas piezas dramáticas descaradas e irreverentes que permitían a los dramaturgos dejar a un lado el necesario restablecimiento del orden perturbado que imponía la preceptiva cómica y, en consecuencia, dejar sin resolver el verdadero conflicto dramático, dando, así, al espectador "un sentimiento de superioridad sobre los personajes, con los que sólo pasajeramente se identifica en el subsuelo común de la flaqueza humana" (Asensio 1971: 39), poniendo encima del escenario una nueva forma de ver el mundo. Una nueva forma de observar las miserias del alma humana, desde el prisma de la comicidad y la algarabía. Un escenario, el del entremés, que ocupara el antihéroe, ese hombre salido del mundo oscuro de subsuelo y engaño de La Celestina, frente a aquellos reyes, bellas damas, astutas criadas y apuestos galanes que protagonizaban las tramas de la nueva comedia surgida tras la estela del Arte nuevo de hacer comedias. Por los caminos oscuros del entremés, y ante los ojos del espectador, circulan viejos ricos celosos, soldados de baja estofa, rufianes, prostitutas, hampones, candidatos a alcaldes analfabetos, adúlteras, titiriteros y hombres de "raza de confeso" (Cervantes 2000: 220). Personajes que marcan las distancias entre ambos tipos de drama, como bien señala Eugenio Asensio:

\footnotetext{
Mientras la comedia de abolengo grecolatino y aspiraciones hidalgas, ellos [criados y plebeyos] sirven para contrastar y realzar al protagonista y sus iguales, en el entremés ascienden a héroes, o quizás a antihéroes, ocupando el centro del tablado (Asensio 1981: 8).
}

Con todo ello se concluye que la clave del entremés no se halla en el argumento, sino en el enfoque que el género brinda a los dramaturgos para recoger viejos temas de la tradición y convertirlos en nuevos espacios de creación, en nuevos mundos al servicio del creador para escudriñar entre los entresijos de las bajezas del individuo. Andando el tiempo, en los textos dramáticos de Federico García Lorca, resurge de nuevo ese enfoque que le empuja a vestir con nuevas galas temas ya clásicos; el género de la farsa y el entremés sirven al granadino para dar de 
nuevo a esos viejos temas su tono de universalidad, de eternidad, de regreso a los orígenes; para volver a dejar "correr esta fuente de maravilla en todo su color antiguo. ¿Antiguo? No. En este caso, eterno” (García Lorca 1997: 240).

Gracias a la concreción y condensación impuesta por la brevedad que caracteriza el entremés ${ }^{3}$, éste construye un espacio en el que aparece la oposición de dos visiones del mundo antagónicas e imposibles de reconciliar. Dos mundos incapaces de entenderse, como el de esas mujeres que viven bajo el yugo de la autoridad paterna para ser cedidas mediante transacción a un marido, al que deberán mostrar la máxima obediencia; es el mundo de la libertad frente al de la tiranía, el mundo de la realidad frente al de la fantasía, es el mundo de Lorenza frente al de Cañizares y el mundo de los titiriteros frente al de los gobernantes; es el mundo de Rosita frente al de su padre y al del bruto don Cristóbal; la libertad de la Zapatera frente a la desconfianza, recelos y recato de su viejo marido y de las vecinas del pueblo; es el mundo de la joven Belisa y sus amantes frente al mundo de tragedia de Perlimplín. Dos mundos en constante oposición, en una lucha de opuestos: los padres y maridos se yerguen en las farsas de García Lorca, como ya lo hicieron en Cervantes y en toda la tradición, en guardianes celosos de la honra de sus hijas o mujeres, quienes a su vez, cada una en su medida, se rebelarán contra el espacio que la sociedad ha reservado para ellas. Las mujeres del entremés se enfrentan a su situación, se rebelan contra sus maridos; es la rebelión contra el poder. Cada uno de los personajes que protagoniza estas breves piezas teatrales se convierte en representación de un mundo, siempre opuesto, siempre en tensión, que en el fondo remite a la ya clásica lucha del individuo por la libertad.

Uno de los temas recurrentes del entremés, la farsa y el teatro breve del Siglo de Oro, y que se convierten en recreación artística de esta oposición entre la libertad del hombre y el poder establecido por la sociedad, lo encontramos en la condena de la práctica de los matrimonios concertados entre un adinerado vejete y una joven adolescente de familia humilde. Falsos matrimonios que se convierten, en los textos de Cervantes, no en un fin, sino en un pretexto para ahondar en la realidad social, la de la España de la primera mitad del siglo XVII, que se extiende a lo largo de los textos del escritor manchego, ya que el género breve le permitía "poner en tela de juicio todo un sistema de valores" (Spadaccini 2000: 18) de una sociedad en cons-

3. "En tan breve texto dramático el entremés se ve obligado a agolpar toda la materia argumental, cuya presentación al público ha de resultar condensada y accesible. Ningún medio mejor para ello que ofrecer en breve apunte el enfrentamiento de opuestos [...] que lleva implícito el antagonismo de dos concepciones del mundo sin posibilidad de casación” (Huerta Calvo 1995: 77). 
tante tensión. Una tensión que nace del enfrentamiento entre la sociedad y aquellos individuos que se aparatan de las normas establecidas, del espacio que la sociedad ha establecido para ellos. Esta necesidad de poner ante los ojos del espectador esta sociedad en la que los que viven en los márgenes de lo establecido no tienen cabida, se convierte en una de las encrucijadas en la que se encuentran de nuevo Federico García Lorca y Miguel de Cervantes. De nuevo, el género farsesco sirve al dramaturgo granadino para reflexionar acerca de los individuos marginales, de aquellos que pasean por los márgenes de lo que la sociedad ha dispuesto para ellos: la joven Rosita que desea convertirse en perro antes que casarse ${ }^{4}$; el títere pelele de Perlimplín que acaba tramando una gran venganza; el vendaval de la Zapatera enfrentada a todo un pueblo. Una encrucijada en la que ambos autores siguen dejando a sus personajes al margen de esta sociedad que les señala al final de la obra.

Elección de un género, el de la farsa y el entremés, llevada a cabo de manera consciente, esmerada y reflexiva. Una vez elegida la forma en que llevará a cabo la plasmación artística de los necesarios caminos del hombre hacia la libertad, Federico García Lorca toma como maestro a Cervantes que "ha hecho sus paces con el barro humano y se divierte con el espectáculo de sus miserias" (Asensio 1981: 42). Miserias que el escritor manchego no juzga, sino que las pone ante los ojos de los espectadores con la intención de plasmar las carencias sociales, económicas y morales que acechaban la España de principios del siglo XVII; el dramaturgo sube así a escena "una reflexión sobre las destemplanzas del ser humano que aflora de las actitudes desequilibradas y desequilibrantes de varios de sus protagonistas (Huerta Calvo 2008: 158). Miserias que sobrevolaban de nuevo por encima de la sociedad española de los años veinte y que de nuevo el dramaturgo granadino se creía con la necesidad de subir a las tablas. Miserias humanas, todas ellas, con las que construye personajes, bien sean burlescos como los títeres de La tragicomedia de don Cristóbal y la señá Rosita, bien sean entrañables como el matrimonio de zapateros, o bien lleguen a alcanzar altas cotas de tragedia como el grotesco Perlimplín. El discípulo recoge al maestro, lo saca del armario y construye un original mundinuevo ${ }^{5}$. Con todo ello el entremés se convierte así en un espacio que "acepta

4. “¡Pero yo digo que los perros se casan con quien quieren y lo pasan muy bien! ¡Cómo me gustaría ser perro!” (García Lorca 1996: 46).

5. "Mundinovi o Mundinuevo: Cierta arca en forma de escaparate, que trahen acuestas los Saboyardos, la qual se abre en tres partes, y dentro se ven varias figurillas de madera movibles, y metiendo por detrás una llave en un agujero, prende en un hierro, que dándole vueltas con ella, hace que las figurillas anden alrededor, mientras él canta una cancioncilla. Otros hai que se ven por un vidrio graduado, que aumenta los objetos y van pasando varias perspectivas de Palacios, jardines y otras cosas" (Autoridades, 1734). 
alegremente el caos del mundo ya que su materia especial son las lacras e imperfecciones de la sociedad coetánea y de las mismas instituciones humanas" (Asensio 1971: 39). Caos, imperfección, lacras de la institución humana que, surgidas del entremés, encuentran un nuevo espacio en las farsas de Federico García Lorca.

\section{Viejos maridos, matrimonios por interés: cuando la libertad queda relegada}

Hay un personaje que recorre siglos de tradición literaria y que encuentra en el entremés el mejor espacio para crecer: el vejete. Esa "figura sobre la que, de suerte indefectible, recaen todas las burlas, palos y agravios. Represor del inagotable instinto de su mujer, cae víctima de ella, que se venga haciéndole adulterio y maldiciéndole a sus espaldas" (Huerta Calvo 1995: 71). Ese viejo, originario del Pantaleón de la Commedia dell'arte, al que Federico García Lorca irá vistiendo de distintas galas a medida que vaya tejiendo el ciclo farsesco. Los matrimonios entre viejos adinerados y jóvenes mujeres de familia humilde, nos conducen a otro de los grandes temas que hunde sus raíces en los orígenes del teatro; de este modo el matrimonio como negocio se convertirá en el trasunto perfecto para ambos dramaturgos de las vilezas de la condición humana. Tanto en el entremés cervantino como en los textos del ciclo farsesco lorquiano, el matrimonio se transforma en un espacio corrupto en el que las mujeres quedan convertidas en objeto del deseo a poseer, un espacio, el del matrimonio por interés, en el que se establece una relación de poder y sumisión entre sus participantes hasta que finalmente se convierte en una "lección de escarmiento dada por la experiencia a quienes, después de torcer el curso natural del matrimonio que debe ser libre y entre iguales" (Asensio 1981: 24).

Don Cristóbal, el hombre panzudo, presuntuoso y grotesco que compra a su esposa por unas onzas de oro, es el primer viejo que crea Federico García Lorca para su teatro de títeres, un viejo muñeco grotesco al que volverá años más tarde con el Retablillo de don Cristóbal y doña Rosita. Personaje en el que se observa la perfecta encrucijada en la que confluyen desde aquellos títeres de los primeros juglares, pasando por modelo del vejete cervantino, hasta llegar a la Commedia dell'arte:

POETA

Usted es un puntal del teatro, don Cristóbal. Todo el teatro nace de usted [...]. Yo creo que el teatro tiene que volver a usted (García Lorca 1992: 33).

En la ruda marioneta, viejo que maltrata al resto de personajes de la farsa, cuajan a la perfección los rasgos de uno de los personajes más característicos de la Commedia dell'arte: Polichinela. El dramaturgo granadino alude a su pasado como 
sirviente de "tal don Pantalón” (García Lorca 1996: 51), por lo tanto estamos ante un personaje que, pese a sus ínfulas de grandeza, su vanidad y presunción, se trata de un criado; Lorca transforma a este viejo dispuesto a comprar cualquier cosa por dinero en un criado, en aquellos zannis que servían a don Pantaleón, pero no en Arlequín o en Pierrot sino que el dramaturgo convierte al futuro marido de doña Rosita en un trasunto oscuro y grotesco de Polichinela ${ }^{6}$.

Este viejo marido, junto con el padre de Rosita, se transfigura, como los viejos cervantinos, en un modelo subversión de la autoridad y del poder que esta desentraña; ambos se hallan en manos de los personajes más desdeñosos y zafios. El poder está en manos del gordo muñeco que quiere poseer a la joven Rosita y del padre que vende a su hija al mejor postor; seres grotescos que se alimentan de los viejos celosos cervantinos que encierran a sus mujeres. Don Cristóbal se convierte así en el punto de partida, es en este primer muñeco donde empieza a construirse todo el mundo del retablo farsesco lorquiano: un viejo a medio camino entre el Cañizares de El viejo celoso y el trágico Carrizales de El celoso estremeño que "viene vestido de verde con un vientre enorme y un poco joroba" (García Lorca 1996: 51) y hace uso de dinero para comprar a Rosita a su autoritario padre arruinado. Un matrimonio entre un viejo adinerado y una joven sin dote que nos devuelve el eco de las palabras de Carrizales:

Había muerto en él la gana de volver al inquieto trato de las mercancías, y parecíale
que, conforme a los años que tenía, le sobraban dineros para pasar la vida [...].
Y estando resuelto en esto, y no lo estando en lo que había de hacer de su vida, quiso
su suerte que, pasando un día por una calle, alzase los ojos y viese a una ventana ${ }^{7}$

6. "Se presenta como el principal rival de Arlequín: apareció con toda seguridad a comienzos del siglo XVII [...]. Polichinela es casi la única de las figuras de la Commedia dell'arte que tiene dos trajes completamente diferentes [...] Cuando un inglés piensa en él ve un personaje jorobado, una abultada panza y tocado con un sombrero cónico. Su media máscara lleva una nariz aguileña, una frente pequeña y una gran verruga en la frente [...]. Por otro lado, no hay duda que en Nápoles [...] Polichinela empezó por llevar el descuidado traje blanco de Zanni [...]. Uno de sus primeros retratos lo representa como un hombre viejo, sin joroba [...]. La característica principal de sus parlamentos parece haber consistido en una especie de ingenio estúpido o estupidez ingeniosa esencialmente grosera y vulgar, que muchas veces se expresaba mediante toscas comparaciones, en las que las emociones más elegantes y los hechos más espirituales quedaban rebajados hasta el realismo más crudo" (Allardyce 1977: 98-99).

7. Del mismo modo que Carrizales encuentra a su joven esposa posada ante la ventana, y que las damas del teatro áureo encuentran en los balcones el espacio para el amor, en el ciclo farsesco lorquiano se produce una subversión de ese espacio ya clásico desde la joven Rosita, quien cierra el balcón a su estimado Cocoliche después de saber que no podrá casarse con él; pasando por la furiosa Zapatera, quien se pasa los días coqueteando con sus pretendientes ante la ventana; hasta llegar al balcón por el que Belisa dejará entrar a todos sus amantes. 
puesta una doncella, al parecer de la edad de trece a catorce años, de tan agradable rostro (Cervantes 2005: 257).

Si algo caracteriza a los viejos cervantinos es el sentimiento de posesión y celos que les invade el alma. Federico García Lorca recupera este oscuro sentimiento y el viejo muñeco en el cuadro sexto, desata su ira por los celos que siente ante la presencia en su dormitorio de Currito y Cocoliche: "¡Te mato, te trituro, te machaco los huesos! ¡Ya me las pagarás, señá Rosita, mala mujer! ¡Con cien duros que me has costado!" (García Lorca 1996: 76). Los celos del viejo marido, un tema ya universal, sirvió al maestro manchego para construir dos plasmaciones artísticas de distinto cariz de un mismo problema; por un lado, en el entremés del Viejo Celoso, Cervantes utiliza el género farsesco para criticar esos matrimonios de conveniencia por dinero entre jóvenes mujeres y viejos adinerados, tan de moda en el siglo XVII, mientras que el mismo tema se volvió trágico cuando lo plasmó en la novela ejemplar del Celoso estremeño; se trata del reverso y el anverso de la vieja moneda de los celos. Es esto, en el fondo, lo que el dramaturgo granadino aprende de Miguel de Cervantes. Retoma de nuevo Federico García Lorca, la posibilidad de dar, a través de distintas formas, un carácter de universalidad a temas clásicos que acompañan al individuo desde tiempos ancestrales; distintas formas, que en ningún momento perderán su originalidad, construyendo así, de forma magistral un retablo farsesco de tres hojas en el que aunar tradición y modernidad. Es por ello que en la Tragicomedia de don Cristóbal y la señá Rosita, ya asoma su preocupación por la opresión que ejerce el poder sobre aquel que pretende alejarse de aquello establecido por la norma social; una preocupación que aquí se viste de farsa, pero que el dramaturgo no abandonará a lo largo de su producción, del mismo modo que Cervantes no abandonó a sus seres marginales de baja estofa a lo largo de su trayectoria literaria. Un poder que, en el caso de la Tragicomedia, hace que doña Rosita, acabe en brazos de este títere grotesco que pone de relieve "lo bajo material" (Cardinali 1998: 32) entregada por su propio padre a cambio de dinero:

Pues no hay más remedio. Ese hombre tiene mucho oro y a mí me conviene, porque si no, mañana tendríamos que pedir limosna (García Lorca 1996: 46).

Pero, dado que en este primer paso del ciclo farsesco, Federico García Lorca se propuso construir una pieza en la que el humor y el llanto de sus personajes caminan de la mano bajo el epígrafe de tragicomedia, concede a Rosita la posibilidad de salvarse de vivir condenada con el viejo tripudo de la porra. Por ello, al final del cuadro sexto, y tras una cómica escena de enredo y caos, tiene lugar 
la muerte ridícula y grotesca de don Cristóbal cuando "la porra se la cae de la mano, y se siente un gran estrépito de muelles" (García Lorca 1996: 78) y tras la muerte se sucede la marcha fúnebre que nos acerca a la tradición carnavalesca del Medioevo:

El penúltimo rasgo profanador del carnaval y las marionetas es adornar grotescamente al muerto ${ }^{8}$ y enterrarlo con una ceremonia sacrílega y jubilosa que invierte los términos de las ceremonias oficiales (Bajtin 1974: 182).

Cerrada la hoja del retablo del teatro de títeres, Federico García Lorca da un nuevo paso adelante con el vuelo airoso de La zapatera prodigiosa. Los viejos cervantinos, como Carrizales y Cañizares, acuden al matrimonio por la necesidad de no estar solos, más que por amor; de la misma forma que el Zapatero ${ }^{9}$ deja claro los motivos por los cuales se casó con su mujer al maldecir a su hermana: "Mi hermana, mi hermana tiene la culpa, mi hermana que se empeñó: ¡que si te vas a quedar solo, que si qué sé yo! Y esto es mi ruina" (García Lorca 1996: 202); el Zapatero llegará incluso a afirmar que no quiere a su esposa ${ }^{10}$. De nuevo el poeta teje con fino hilo tradición y modernidad a la luz de las palabras que el viejo Cañizares le espeta a su compadre:

Señor compadre, señor compadre: el sesentón que se casa con quince, o carece de entendimiento, o tiene gana de visitar otro mundo lo más presto que le sea posible. Apenas me casé con doña Lorencica, pensando en tener en ella compañía y regalo, y persona que se hallase en mi cabecera y me cerrase los ojos al tiempo de mi muerte (Cervantes 2000: 263).

El viejo y la niña, renacen así en el terreno de la farsa cuando Federico García Lorca rescata de nuevo a esta pareja de personajes del arquetipo vetusto en que la escena de finales del siglo XIX les había convertido. De este modo, la joven zapa-

8. "Traen un ataúd enorme, en el que hay pintados pimientos y rábanos en vez de estrellas. Los curas vienen cantando. Marcha fúnebre de pitos" (García Lorca 1996: 78).

9. No debemos perder de vista, como bien señala la profesora Rodríguez Cachero que el oficio de zapatero acompañó a una serie de personajes muy bien tipificados ya en los entremeses y en los textos cervantinos que "Lorca va transformando según las exigencias de cada farsa" ( Josa 2003: 223). Un personaje, el del zapatero, sobre el que planea cierta ingenuidad e inocencia, con un carácter conformista y cuya ocupación está bastante alejada de la intelectualidad, que desde La guarda cuidadosa llega hasta Cansa-Almas en la Tragicomedia, de nuevo aquel que debe poner el zapato a la mujer por la que disputan dos hombres; y al Zapatero de la farsa violenta con el que pretende dar un paso más allá del estereotipo tradicional.

10. "pero yo no estoy enamorado de mi mujer" (García Lorca 1996: 206). 
terilla no tardará ${ }^{11}$ en echar en cara a su viejo marido la diferencia de edad que les separa; enfrentamiento entre la Zapatera y su marido que surge en la tercera escena del primer acto:

ZAPATERA. También me aguanto yo... piensa que tengo dieciocho años.

ZAPATERo. Y yo... cincuenta y tres. Por eso me callo y no me disgusto contigo... ¡demasiado sé yo!... (García Lorca 1996: 200).

Los lamentos del viejo Zapatero tras haberse casado con su joven esposa en búsqueda de compañía y empujado por sus hermanas "por su dinerillo y su salud" (García Lorca 1996: 206), nos devuelven a las palabras del Vejete del Juez de los divorcios:

Y ya va para dos años que cada día me va dando vaivenes y empujones hacia la sepultura, a cuyas voces me tiene medio sordo, y a puro reñir, sin juicio (Cervantes 2000: 100).

Es en ese gesto furioso de la Zapatera, una vez cerrada la puerta y en la soledad de su casa ${ }^{12}$, con el que el dramaturgo da entrada al imaginario cervantino para construir el verdadero conflicto de la zapaterita; es en este momento en el que en la voz de la fiera resuenan los ecos de la Mariana de El juez de los divorcios o de la Lorenza de El viejo celoso. Cervantes se convierte así no solo en una provechosa fuente temática sino en una suerte de imaginería que ayuda a Lorca a la construcción de sus personajes, ya que si al otro lado del espejo de la Zapatera encontramos a un amplio abanico de mujeres cervantinas, su marido deberá gran parte de su talla a personajes a como el viejo Cañizares. Entremeses todos ellos con un punto de partida común: el matrimonio entre una joven y humilde mujer y un adinerado y poderoso viejo; matrimonios que sirven a Cervantes como pretexto para ahondar en la realidad social del siglo XVII y a Federico García Lorca para poner ante los ojos del público "de una manera simple, y accesible a todos, esa gran disconformidad del alma con lo que le rodea” (García Lorca 1997: 477).

11. "Desde el primer momento, la obra exhibe de manera hiperbólica todos los lugares comunes que la tradición había asignado al tema del viejo y la niña: la culpa de los casamenteros, la infidelidad de la niña, las quejas, los escándalos” (Fernández Cifuentes 1992: 93).

12. A diferencia de sus predecesoras, Leonora o Lorenza, la Zapatera no se siente prisionera en su casa. La casa como elemento que está a medio camino entre el convento y la cárcel, bajo la cual viven encerradas por sus viejos maridos las mujeres cervantinas, se convierte en la farsa de Federico García Lorca, en un acto de maestra distorsión en el refugio de la Zapatera acechada por una realidad que coarta su libertad. 
Matrimonio por interés económico que no tarda en asomar por la farsa de nuevo, al más puro estilo cervantino, como motivo literario que el dramaturgo granadino trasciende para elevar el conflicto de la Zapatera y hacerlo universal; para subir a escena la historia de la libertad del alma humana atrapada entre dos mundos, el mundo de la realidad y el de la fantasía. Un matrimonio que "ha nacido lastrado, según se nos dice, por motivos ajenos al amor: la soledad del maduro zapatero, la pobreza de la juvenil zapatera" (Hernández 1982: 53). Matrimonios lastrados también, los de los textos cervantinos, en los que las esposas, del mismo modo que la Zapatera, reclaman su libertad; personajes femeninos que de uno u otro modo, con más o menos suerte, se enfrentan a su situación y cuya rebeldía marca su acentuado carácter. Mujeres y conflictos clásicos que andando el tiempo se convierten, en las piezas farsescas de Federico García Lorca, en la posibilidad de dar voz a las almas poéticas que luchan por ser libres dentro de un mundo que las atrapa. Las discusiones y desencuentros que vertebran toda la farsa no parecen ahora tan lejanos a los gritos de las mujeres que desfilan por delante del Juez de los divorcios, la joven Mariana se lamenta de "el ivierno de mi marido, y la primavera de mi edad; el quitarme el sueño por levantarme a media noche a calentar paños y saquillos de salvado" (Cervantes 2000: 99); ni a los lamentos de la joven Lorenza hacía su esposo: "¡Ahora echo de ver quién eres, viejo maldito, que hasta aquí he vivido engañada contigo!" (Cervantes 2000: 271).

Varios son los puntos de encuentro entre La zapatera prodigiosa y los textos cervantinos. Uno de ellos es el interés económico que subyace bajo estos matrimonios, es decir, se trata un matrimonio, el del viejo y la niña, que se contrae, en la mayor parte de las ocasiones, por un interés económico de la familia que empuja a sus jóvenes hijas hacía la infelicidad más profunda. Interés económico que el Zapatero echa en cara a su joven esposa en plena discusión, "Eres mi mujer, quieras o no quieras, y yo soy tú esposo. Estabas pereciendo, sin camisa ni hogar. ¿Por qué me has querido?" (García Lorca 1996: 201); el mismo interés que encontramos en el desdichado matrimonio de Lorenza, "Y aún con esos y otros semejantes villancicos o refranes me engañaron a mí. ¡Qué malditos sean sus dineros, fuera de las cruces, malditas sus joyas, malditas sus galas, y maldito cuanto me da y promete!" (Cervantes 2000: 257); la misma riqueza bajo la que se entrega a Leonora al viejo celoso extremeño:

Como un rico menaje para adornar la casa, de modo que tapicerías, estrados y doseles ricos mostraba ser de un gran señor; compró asimismo, cuatro esclavas blancas, y herrolas en el rostro, y otras dos negras bozales [...]; y teniéndolo todo así aderezado y compuesto, se fue a casa de sus suegros y pidió a su mujer, que se la entregaron 
no con pocas lágrimas, porque les pareció que se la llevaban a la sepultura (Cervantes 2005: 332-333).

Matrimonios por interés que corrompen las relaciones entre hombres y mujeres; matrimonios que además brindan la posibilidad a Cervantes de ofrecer distintas versiones de un motivo ya clásico. Es por ello que el espectro de actitudes de las mujeres cervantinas se extiende desde las contestatarias y gritonas Mariana ${ }^{13} \mathrm{y}$ Guiomar, pasando por la sumisa Leonora ${ }^{14}$, hasta llegar a la furtiva y adúltera Lorenza; cada una de ellas elige su modo de enfrentarse a la represión del poder que representan sus maridos. De todas ellas la zapaterita está más cercana a las dos primeras que no a Lorenza o Leonora, si tenemos en cuenta que la protagonista de la farsa violenta no se muestra sumisa en ningún momento frente a las ordenes de su marido y que, pese a sus coqueteos públicos, jamás se le pasa por la cabeza perder su honra con el adulterio, porque ante todo ella piensa en su honra, en su libertad, y no en la de su marido. Una actitud que la hace convertirse en la verdadera protagonista de la farsa, alrededor de la cual danzan el resto de personajes; la furia de la Zapatera y sus reacciones ante los elementos externos que la rodean, condicionan las respuestas de su marido, de sus pretendientes y de sus vecinas, marcando así el ritmo de todo el texto.

La Zapatera es una farsa, más bien un ejemplo poético del alma humana y es ella sola la que tiene importancia en la obra. Los demás personajes la sirven y nada más (García Lorca 1997: 408).

Las últimas galas con las que se vestirá este vejete cervantino dentro del retablo del ciclo lorquiano hunde sus raíces en la Commedia dell'arte puesto que "los rasgos esenciales de Pantalón-avaricia e impotencia sexual- pasan, pues, al Vejete entremesil" (Huerta Calvo 1995: 132); son las del Amor de don Perlimplín con Belisa en su jardín. Galas, las de este nuevo personaje con las que el Federico García Lorca consigue alcanzar altas cotas de perfección en la reconstrucción de este tradicional personaje. Con don Perlimplín, el dramaturgo granadino consigue de nuevo alcanzar el gran hito de Miguel de Cervantes con los personajes de sus

13. "Y va para dos años que cada día me va dando vaivenes y empujones hacía la sepultura, a cuyas voces me tiene medio sordo y, a puro reñir sin juicio [...]. En resolución, señores, yo soy el que muero en su poder, y ella es la que vive con el mío" (Cervantes 2000: 100).

14. "No se desmandaban sus pensamientos a salir de las paredes de su casa, ni su voluntad deseaba otra cosa más de aquella que la de su marido quería; solo los días que iba a misa veía las calles" (Cervantes 2005: 335). 
entremeses, "procura relatar con moderno colorido formas variantes de una locura u obsesión" (Asensio 1981: 41). La farsa del amor imposible de don Perlimplín parece surgir como un fin de ciclo; esta pequeña aleluya se convertirá en puerto de llegada de todo lo trabajado en las farsas anteriores y puerto de salida para ese nuevo teatro de poético que en gran parte quedó inconcluso y que el propio dramaturgo tildaba de irrepresentable, como bien apunta el profesor Luis Fernández Cifuentes:

Perlimplín se comportaba así, en más de un sentido, como el único (o el más claro) indicio de aquel otro teatro llamado difícil o irrepresentable que - secretamente había de llevar a sus últimas consecuencias los experimentos de esta aleluya. Al mismo tiempo Perlimplín resultaba también el último y el más brillante de sus ejercicios de espectacularidad (Fernández Cifuentes 1986: 117).

El viejo Perlimplín, igual que el marido de la Zapatera, y los vejetes cervantinos ya citados, acude titubeante al matrimonio empujado por la criada Marcolfa hasta el balcón ${ }^{15}$ donde la bella Belisa aparece medio desnuda:

Perlimplín. (Angustiado). Pero Marcolfa... ¿por qué sí? Cuando yo era niño una mujer estranguló a su esposo. Era zapatero ${ }^{16}$. No se me olvida. Siempre he pensado no casarme. Yo con mis libros tengo bastante. ¿De qué me va a servir?

15. Federico García Lorca cuida hasta el último detalle de esta pequeña aleluya erótica, los espacios, al igual que el resto de elementos de la obra, no son elegidos al azar. El dramaturgo elige el balcón, espacio que remite al teatro de los hermanos Quintero y de Echegaray, para el cuadro primero en el Perlimplín pide en matrimonio a la joven Belisa; el dormitorio, "proyección del interior turbulento de Perlimplín, aterrorizado al tener que enfrentarse a una experiencia aún no vivida que se le presenta grande y pesada como la cama que se tiene ante él, y, a su vez como censura del voyerismo intrínseco del espectador de la comedia burguesa [...] empeñado en confundir el teatro con la representación escénica de "trocitos de vida" con los que sentirse identificados" (Peral Vega 2004: 699), se convierte en el espacio donde se consuma el adulterio de Belisa en el cuadro segundo; en el comedor del cuadro tercero es dónde aparece por primera vez la sombra del amante desconocido, transgrediendo así el espacio prototípico de la comedia burguesa; y finalmente el Jardín, el espacio típicamente romántico, destinado al encuentro de los amantes, se convertirá ahora en el espacio de la tragedia.

16. Es importante anotar que el propio Federico García consideró La zapatera prodigiosa y el aleluya de don Perlimplín como dos obras emparentadas dentro del ciclo farsesco, tanto es así que se representan juntas en la función del Club Anfistora de 1933. Ambas comparten un mismo punto de partida, el matrimonio entre viejos y niñas, pero mientras, y como bien apunta Francisco García Lorca, la farsa violenta se convierte en un texto de estructura abierta en la que los personajes terminan en el mismo punto en el que empezaron el viejo Perlimplín y su joven esposa: Los personajes de La zapatera continúan siendo iguales a sí mismos a lo largo de los dos actos de la farsa; no así el Perlimplín, cuya muerte es una transfiguración, ni Belisa, que ha dejado también de ser lo que era, "recreada" por la muerte de Perlimplín (García Lorca 1990: 319). 
MARCOLFA. El matrimonio tiene grandes encantos, mi señor. No es lo que se ve por fuera. Está lleno de cosas ocultas. Cosas que no está bien que sean dichas por una servidora... (García Lorca 1996: 243).

Don Perlimplín, cuyo nombre ya nos remite a un mundo grotesco y ridículo, se convierte en manos de ambas, junto con la madre de Belisa, durante los dos primeros cuadros, en una pequeña marioneta que baila al son que marcan las mujeres. Pese a ello, el cambio que opera en el carácter del viejo marcará la estructura de la obra, es decir, Federico García Lorca, construye la aleluya bajo una estructura bimembre en la que los dos primeros cuadros estarían marcados por la autoridad de Marcolfa, los deseos de la madre de Belisa y el cuerpo de la propia Belisa, mientras que tras la aparición de los duendes, en los cuadros tercero y cuarto, con la transformación de Perlimplín en el amante de la capa roja, nace el mundo de la imaginación, el lenguaje de la poesía con el que el protagonista invierte los papeles y dicta ahora el devenir de los acontecimientos y de las almas del resto de personajes. Si en la Tragicomedia de don Cristóbal quien empujaba a la joven a manos del vejete adinerado era su padre, en este caso quien entrega a su hija por dinero es la madre; de nuevo, en el último escalón del ciclo, el matrimonio se convierte en un negocio y en un espacio corrupto del que solo puede surgir "una bandada de pájaros de papel negro" (García Lorca 1996: 246), presagio de la tragedia:

Madre (a Belisa). Don Perlimplín tiene muchas tierras. En las tierras hay muchos gansos y ovejas. Las ovejas se llevan al mercado. En el mercado dan dineros por ellas. Los dineros dan la hermosura... y la hermosura es codiciada por los demás hombres (García Lorca 1996: 244).

Federico García Lorca hace converger de nuevo, en el viejo Perlimplín las dos tradiciones que ya hemos apuntado anteriormente, por un lado los cornudos vejetes cervantinos junto con el ingenuo Pancracio de La cueva de Salamanca ${ }^{17}$, incapaz de distinguir entre la realidad y la ficción; y por otro, "comparte con Pierrot su mundo ideal forjado entre versos, propios o ajenos, su imposibilidad atávica para la consumación del amor, su destino trágico y [...] el dolor como fuente máxima de inspiración" (Peral Vega 2004: 696-697). Este el viejo casado con una joven mujer a la que no es capaz de satisfacer, se convierte en la última faceta de un proceso que el dramaturgo había iniciado con la Tragicomedia de don Cristóbal y la señá Rosita encaminado, en cuanto a los personajes masculinos se refiere, a la

17. "Diréle unas palabras que sé al oído, que tienen virtud para hacer volver de los desmayos" (Cervantes 2000: 238). 
"dignificación de un tipo -el cornudo-, que había sido fuente de comicidad en el teatro español del Siglo de Oro" (Peral Vega 2001: 180). Un proceso de humanización que le conduce a la creación de un personaje en el que concurren dos máscaras típicas de la Commedia dell'arte, por un lado, el viejo, ridículo e impotente Pantalone; y por otro lado, el Pierrot nacido de la mano de los simbolistas franceses de fin de siglo en el que hallaron "la encarnación de un espíritu disidente, una continua lucha con el mundo que le rodea e, incluso, con su propia conciencia; un perdedor cuya vida se basa en una cruel paradoja, ya que encuentra en el sufrimiento el caldo de cultivo para su creatividad" (Peral Vega 2001:31).

Con la tragedia de don Perlimplín, el dramaturgo granadino construye un nuevo personaje bajo el que subyace el mejor tejido de la tradición. De los tres vejetes que forman parte del ciclo farsesco, don Perlimplín se convierte en el puerto final de un viaje que inició con la Tragicomedia, un viaje marcado por la subversión y la evolución de varios motivos y que ahora le permite alcanzar un texto con espacios y escenas más depurado, eliminando aquello innecesario de la escena, para poder mostrar al público la esencia del alma humana, lo más primitivo del hombre y por ello universal. La aleluya se convierte en el broche final de un ciclo del que Federico García Lorca afirmaba: "Lo que me ha interesado de don Perlimplín es subrayar el contraste entre lo lírico y lo grotesco y aún mezclarlos en todo momento" (García Lorca 1997: 409).

\section{Bibliografía}

ALLARDYCE, N. (1977). El mundo de Arlequín. Estudio crítico de la Commedia dell'arte. Barcelona: Barral.

ASENSIO, E. (1971). Itinerario del entremés. Madrid: Gredos.

ASENSIO, E. (1981). "Introducción" en Entremeses (Miguel de Cervantes). Madrid: Castalia.

BAJTIN, M. (1974). La cultura popular en la Edad Media y el Renacimiento. Barcelona: Seix Barral.

CANAVAGGIO, J. (1983). "García Lorca ante el entremés cervantino” en El teatro menor en España a partir del siglo XVI. Actas del Coloquio celebrado en Madrid, 20-22 de mayo de 1982. Madrid: CSIC. (Anejos de la Revista Segismundo, 5).

CARDINALI, A. (1998). "Introducción" en Títeres de Cachiporra. Tragicomedia de don Cristóbal y la señá Rosita (Federico García Lorca). Madrid: Cátedra. CERVANTES, M. de (2000). Entremeses. Madrid: Cátedra.

CERVANTES, M. de (2005). Novelas Ejemplares. Barcelona: Galaxia Gutenberg. 
FERNÁNDEZ CIFUENTES, L. (1986). García Lorca en el teatro: la norma y la diferencia. Zaragoza: Prensas Universitarias de Zaragoza.

FERNÁNDEZ CIFUENTES, L. (1992). "El viejo y la niña: tradición y modernidad en el teatro de García Lorca" en El teatro en España. Entre la tradición y la vanguardia (1918-1939). (Coord. Dru Dougherty y María Francisca Vilches de Frutos). Madrid: CSIC-Fundación Federico García Lorca.

GARCÍA LORCA, F. (1996). Obras Completas II. Teatro. Barcelona: Galaxia Gutenberg.

GARCÍA LORCA, F. (1992). Retablillo de don Cristóbal y doña Rosita. Aleluya popular basada en el viejo y desvergonzado guiñol andaluz (versión inédita de Buenos Aires) (ed. Mario Hernández). Granada: Diputación Provincial de Granada.

GARCÍA LORCA, F. (1997). Obras Completas III. Prosa. Barcelona: Galaxia Gutenberg.

GARCÍA LORCA, F. (1990). Federico y su mundo. Madrid: Alianza.

HERNÁNDEZ, M. (1982). "Una criatura quijotesca: La zapatera prodigiosa (Cervantes, Falla, García Lorca)". Teatro en España 10: 46-53.

HUERTA CALVO, J. (1995). El nuevo mundo de la risa. Estudios sobre el teatro breve y la comicidad en los Siglos de Oro. Palma de Mallorca: José J. de Olañeta editor.

HUERTA CALVO, J. (ed.) (2008). Historia del teatro breve en España. Madrid, Iberoamericana-Vervuert.

JOSA FERNÁNDEZ, L. (2003). "De farsa humana eterna... Federico García Lorca y Cervantes" en Theatralia. El teatro de Miguel de Cervantes ante el IV Centenario. Pontevedra: Mirabel.

PERAL VEGA, E. J. (2001). Formas del teatro breve español en el siglo XX (18921939). Madrid: Fundación Universitaria Española.

PERAL VEGA, E. J. (2004). "Morir y matar amando: Amor de don Perlimplín con Belisa en su jardín”. Arbor 699-700: 691-702.

SPADACCINI, N. (2000). "Introducción” en Entremeses (Miguel de Cervantes). Madrid: Cátedra.

UCELAY, M. (2005). “Introducción”, Amor de Don Perlimplín con Belisa en su Jardín. Madrid: Cátedra. 